\title{
A Manuscript Regarding Physicians' Suicidal Death Resulting from Psychological Stress in their Inner World (355)
}

\author{
Gerald C Hsu* \\ eclaireMD Foundation, USA
}

Submission: November 05, 2020; Published: November 12, 2020

*Corresponding author: Gerald C Hsu, eclaireMD Foundation, USA

\begin{abstract}
The author is a 73-year-old medical research scientist who recently read an article regarding physician health and death [1]. Inspired by the story and his own past experiences, he decided to write a special manuscript to be shared with medical doctors. This article has a different writing style compared to his previous 354 math-physical medicine research papers, based on a quantitative method to derive analysis results with high precision, aimed at helping patients.
\end{abstract}

The goal of helping patients must go through the delivery channel of physicians and surgeons, while being concerned about the psychological health of medical doctors. This is the reason why he wrote this article with a qualitative style with an aim at medical physicians.

Being a physician is an enviable profession, where they greatly invested and sacrificed to reach to where they are today. In terms of financial rewards, that is money, even though they are not generously rewarded, at least they are handsomely compensated. With their continuous knowledge, skill improvement, and contribution to society, they may even earn their deserved fame. Their ultimate goal should come from saving people's life, not the same as political or financial power. In the author's opinion, saving lives is the outmost power to achieve; therefore, it is a desirable profession indeed.

By having pride and feeling prestige at commencement by getting their MD degree, the physicians should not allow their accomplishments between the ages from 20 to 30 years of age become the only internal strength and emotional support. They should continuously improve themselves to expand into different areas in exploring new findings, learning additional skills and knowledge. This life-long learning will make a broader and more capable person, even for a physician. These newly gained inner strengths will aid physicians to face new challenges in their life.

However, there is a price to pay from having a decent, enviable, and well-compensated profession. In terms of reducing and controlling stress, burdens, and psychological pressure that comes along with their job, life, and relationships, the author believes that they must go deeper into their own inner world, i.e. their mind and heart, to search for strength. When different types of stress overwhelms them, they must return to their original motivation when they decided to become a physician which is helping their patients. Only this type of compassion in their heart, similar to having faith, can then help them survive many types of tests and challenges they encountered in their profession and private life. For those medical doctors who chose medicine for other reasons, with material or superficial motivations, they should search their heart again to see whether another career is better for them. For example, if their initial motivation was monetary, they better shift their career early enough to be an entrepreneur who takes big risks for larger financial returns.

When physicians face various stressful situations, they should not fight this battle alone. There are plenty of people who would support them as long as they speak up and seek assistance, such as from a mental health professional, like the author did. The author is an educated individual, knowledgeable scientist, and experienced engineer, but more importantly, he had many rich life experiences that were long, colorful, struggling, and challenging. Through his brief self-introduction, the reader can see many similarities and also identify some connections. He cares about his medical colleagues as much as he cares about patients with chronic diseases. This is his motivation of writing this unique manuscript aiming at physicians, even though he knows that it is a unique article with a qualitative style instead of his previously published quantitative research papers.

\section{Introduction}

The author is a 73-year-old medical research scientist who recently read an article regarding physician health and death

(Reference 1). Inspired by the story and his own past experiences, he decided to write a special manuscript to be shared with medical 
doctors. This article has a different writing style compared to his previous 354 math-physical medicine research papers, based on a quantitative method to derive analysis results with high precision, aimed at helping patients. The goal of helping patients must go through the delivery channel of physicians and surgeons, while being concerned about the psychological health of medical doctors. This is the reason why he wrote this article with a qualitative style with an aim at medical physicians.

\section{Background}

\section{Author's brief background}

Every person is allowed to express his or her personal thoughts and opinions. Why should physicians read this manuscript? The author's father was a medical doctor, who started as a surgeon and ended up as an internal medicine physician. When the author was admitted into a medical school, he chose mathematics as his undergraduate major due to the following two reasons. First, he was afraid of the sight of blood (now, he studies hematology, blood, and glucoses). Second, he told his father that he did not want to interface with unhealthy and unhappy patients all day long.

He spent 17 years to study at seven different colleges, where he graduated from one of the top ranked engineering universities. He pursued his career in the fields of aerospace, naval defense, nuclear power, computer hardware and software, and semiconductor chips. After suffering seven business failures over 20 years during his entrepreneur days, he finally became one of the top CEOs in Silicon Valley, where he was generously compensated for his business success. After achieving business success, he has engaged in many charitable and volunteer opportunities. He spent 9 years to self-study psychology, especially abnormal psychology involving traumatized children who developed a variety of personality disorders. He also established four psychotherapy centers and hired four full-time psychiatrists to take care of over 200 patients for four years until he was physically suffering from long-term health problems in 2010.

The stressful business life caused the collapse of his health. He suffered various complications from his metabolic disorder diseases of obesity and diabetes, including five cardiac episodes, kidney problems, diabetic retinopathy, and others. In order to save his life, in July of 2010, he has initiated his decade-long self-study and medical research in the area of endocrinology, diabetes, metabolism, nutrition, and lifestyle. To date, he has written 354 medical papers, attended over 65 international medical conferences, made more than 120 oral presentations, and published over 300 papers in $100+$ medical journals, including nine papers of personal traits and psychological behaviors of patients with chronic diseases [2-10].

Approximately 40 years ago, when he was in his mid-30s and his son was around 7 years old, he took his son to visit a pediatrician in Northern California. At the clinic, a nurse informed him that his son's female pediatrician (around mid-30s as well) had committed suicide in her office a few days earlier. That news shocked him tremendously. At that time, he could not understand why such a young physician with a very promising future would kill herself.

The reason for the brief introduction of the author is to connect himself with physicians who went through similar experiences, who have high degrees of education with difficult disciplines, long and challenging internships, competitive professional struggles, plus financial reward combined with fame, and power, but associated with stress, burnout, depression, and various psychological pressures. Therefore, he understands to some degree, how, why, and what physicians are thinking and doing.

\section{Cited article}

The article he read recently is "Top causes of death among doctors" in Physician Health \& Behavior, by Charlie Williams, published on October 23, 2020 [1].

Here is an excerpt:

\section{First, the good news}

Being a doctor comes with some serious rewards. Helping people overcome sickness and injury is fulfilling. The opportunity to learn and grow never ceases. And the pay isn't too shabby, either. Of course, the career is not without risks. Burnout remains pervasive. Exposure to harmful pathogens, radiation, and chemicals is an everyday possibility. Even though hazards and stress are parts of every job, life as a physician brings its own blend of harms-some of which can be deadly.

Our finding that physicians die older than do others is not unexpected, given the healthy work effect, high socioeconomic status, and prior data showing that physicians tend to make healthy choices. (The author's note: US physicians do have 3\% to $5 \%$ longer expected life than other professionals.) The top 10 causes of death for white male physicians in 1990 (heart disease, cancer, cerebrovascular disease, accidents, COPD, pneumonia/ influenza, diabetes mellitus, suicide, liver disease, and HIV/AIDS) were essentially the same as those of the general population in the same year. On the other hand, these doctors were significantly less likely to die from alcoholism, colorectal cancer, bacterial diseases, respiratory diseases (including lung cancer), digestive system diseases, acute myocardial infarction, and non-ischemic heart disease.

\section{Now, the bad news}

In a few stand-out areas, doctors appear to be at greater risk of dying than the general population: accidents, suicide, and cerebrovascular disease. First, white male physicians were more likely to die from external causes of injury-like transport accidents, accidental poisoning, and self-inflicted injury-as well as hepatitis, malignant melanoma, Alzheimer disease, and pancreatic cancer. 


\section{Second, suicide}

As the cause of death in physicians between $0 \%$ and $4 \%$ of the time which is a significantly higher average than the $0.001 \%$ rate in the general population cited by the American Foundation for Suicide Prevention in 2018. Another article, published in The Journal of the Missouri State Medical Association, cited studies that found suicide rates as much as $40 \%$ higher in male doctors and $130 \%$ higher in female doctors than the general population.

\section{Third, Cerebrovascular diseases}

Like aneurysms, stroke, and arteriovenous malformations, were $9 \%$ more likely to be the cause of death for physicians."

\section{Body of this Article}

Key points Of course, the author has his personal viewpoints regarding both accidental death (i.e. professional hazards) and death from cerebrovascular diseases. But he would like to focus on one specific subject suicidal death in this article. The main discussion point is achieving a peaceful and calmer inner world, i.e. heart and mind.

\section{Three desired targets in life}

Most educated people seek three common targets in their lives, money, fame, and power, in addition to their self-satisfaction (pride) and self-value (esteem). There is nothing wrong to pursue money, fame, or power; however, two importnt points should be mentioned here. First, driving for anything should have a limit, unlike the phrase, "greed is good, greed works" from the 1987 movie Wall Street. Second, for most people, you should choose only one target of the three to focus on. When you try to achieve two or more targets at the same time in your life, disaster usually comes along with it. If you want money, then try to be a businessperson or a professional athlete; if you want fame, then try be a scholar or a movie star; if you want power, then try to be a politician or a financial giant. However, for example, if you want power, fame, and money at the same time, most likely you will end up like a corrupted politician and disaster would come along eventually.

\section{Never forget your original heart}

I always ask myself why I wanted to be "someone" when I was young. Similarly, please ask yourself why you wanted to be a medical doctor when you were young. Medicine is a business sector of giving help and providing service. The most noble and correct answer should be: "I truly want to help relieve the patients from their miserable pain, disease, suffering, and death". Of course, probably some young and smart medical school students might be driven by prestige, image, social-economic status, excellent compensation, and more like most people. There is nothing wrong about wanting to get those things; however, please never forget the ultimate and most important objective of choosing medical career is to help patients. Otherwise, you will never achieve your inner peace, self-fulfilling, and ultimate self-pride. The author was a successful high-tech entrepreneur, but he is not proud of his achievements in that sector. Technology itself has no internal evil, but the real-life applications by human society create a 5050 split which depends on whether you use semiconductor and computer technology to conduct evil or good-will actions. On the contrary, his past 10-years of medical research is his most proud and fulfilling period in his lifetime, as long as he does not associate with any money-driven organizations or profit-oriented activities. His medical research work and its ending results are "pure good, nothing evil at all". Therefore, whenever you are having a doubt about your profession and work, please always go back to your original heart and think about the root of your profession which is "helping patients".

\section{Continuous improvements in life}

When individuals receive the highest degree from the finest educational institute between the ages of 20 to 30 , this selfpride feeling stays with them for the rest of their lives. However, we should not allow our initial accomplishments at a young age become a hinderance to our continuous improvement and future achievements. The author has met more than 1,000 clinical doctors over the past decades. He has noticed some of them lost their interest on continuous improvement by gaining new knowledge. Of course, they can continuously accumulate their empirical knowledge and experiences through seeing and treating more patients, though this is a longer and slower process in comparison with learning from deep and thorough medical research results. The author spent 36 years of his 73 years of life ( $\sim 50 \%$ of his life) on learning and studying 10 different academic disciplines. In the past 10 years, he realized that all of these 10 different disciplines are actually interconnected with each other and can be applied through medicine. During this time, he spent more than 30,000 hour studying and researching medicine. He feels the biomedical system is the most complicated system he has ever touched or studied. As a result, some of his friends laughed at him because he was not enjoying his retirement instead, he was working hard on his research. Helping patients through medical research became his post-retirement hobby. What is more enjoyable than spending your time on your hobby? In summary, life is a long journey which is filled with many surprising turns and interesting explorations. Therefore, do not allow the initial accomplishments to become the hinderance of your continuous success in your future. Learning and growing are a true and long-lasting characteristics of maturity.

\section{Stress, burnout, depression}

Every type of job has its good side, bad side, ups and downs. Stress, burnout, and depression are often inevitable and they go along with any profession you choose. The author has gone through many life hardships, such as shorting money to pay for food, washing 1,000 toilets to pay for tuition, working three years without any income, driving a truck within the US to demonstrate his developed product, being chased by industrial enemy with lawsuits, spending $\$ 1.4$ billion dollars to defend himself, being 
arrested from not violating any laws, being forced to sell his established enterprise due to his poor health, etc.

After having to sell his well-established semiconductor company, a deep and sad inner feeling emerged which is remarkably similar to killing one's own baby, he went through a difficult 3-year depression which required continuous psychological counseling. That was why he began to self-study psychology for 9 years after his business career ended. He heard once from a medical doctor who describes the psychiatrist as a "voodoo doctor". We should not hold any biased opinion against any professional field. Each field has its own strengths and weaknesses, and medicine is no exception. Bias and discrimination against other academic or professional fields only limit our own feasibility of further exploration and continuous growth. When we realize that our stress level from our work, our private life, or our inter-personal relationships become unbearable, we should seek immediate help. We may start seeking help from our family members or trusted friends, but do not stop seeking help from other professionals, such as psychiatrists. Depression, stress, burnout are not shameful, and they should not be hidden. We should speak out and seek help. The act of suicide is a sad and shameful ending that shows a true sign of a loser. No medical doctor should be a loser in life. In particular, physicians should not commit suicide due to wasting the huge investments of family expectation and support, medical education tuition and expenses. and internship struggles. It is important to be a positive example for others to admire and learn from, along with their own additional rewards in their lifetime.

No matter what kind of problems or challenges you are facing now, it may feel unbearable, but it is not the end of the world. Fight against those problems hard with your inner strength and you will succeed eventually. The author has faced many similar challenges in his life and has always survived, even becoming stronger after these difficulties.

\section{Conclusion}

Being a physician is an enviable profession, where they greatly invested and sacrificed to reach to where they are today. In terms of financial rewards, that is money, even though they are not generously rewarded, at least they are handsomely compensated. With their continuous knowledge, skill improvement, and contribution to society, they may even earn their deserved fame. Their ultimate goal should come from saving people's life, not the same as political or financial power. In the author's opinion, saving lives is the outmost power to achieve; therefore, it is a desirable profession indeed.

By having pride and feeling prestige at commencement by getting their MD degree, the physicians should not allow their accomplishments between the ages from 20 to 30 years of age become the only internal strength and emotional support. They should continuously improve themselves to expand into different areas in exploring new findings, learning additional skills and knowledge. This life-long learning will make a broader and more capable person, even for a physician. These newly gained inner strengths will aid physicians to face new challenges in their life.

However, there is a price to pay from having a decent, enviable, and well-compensated profession. In terms of reducing and controlling stress, burdens, and psychological pressure that comes along with their job, life, and relationships, the author believes that they must go deeper into their own inner world, i.e. their mind and heart, to search for strength. When different types of stress overwhelms them, they must return to their original motivation when they decided to become a physician which is helping their patients. Only this type of compassion in their heart, similar to having faith, can then help them survive many types of tests and challenges they encountered in their profession and private life. For those medical doctors who chose medicine for other reasons, with material or superficial motivations, they should search their heart again to see whether another career is better for them. For example, if their initial motivation was monetary, they better shift their career early enough to be an entrepreneur who takes big risks for larger financial returns.

When physicians face various stressful situations, they should not fight this battle alone. There are plenty of people who would support them as long as they speak up and seek assistance, such as from a mental health professional, like the author did. The author is an educated individual, knowledgeable scientist, and experienced engineer, but more importantly, he had many rich life experiences that were long, colorful, struggling, and challenging. Through his brief self-introduction, the reader can see many similarities and also identify some connections. He cares about his medical colleagues as much as he cares about patients with chronic diseases. This is his motivation of writing this unique manuscript aiming at physicians, even though he knows that it is a unique article with a qualitative style instead of his previously published quantitative research papers.

\section{References}

1. William Charlie (2020) Physician Health \& Behavior. Top causes of death among doctors.

2. Hsu Gerald C (2020) Behavior psychology and body weight reduction of a T2D patient using GH-Method: math-physical medicine or mentalitypersonality modeling. Eclaire MD Foundation, USA.

3. Hsu Gerald C (2020) Glucose control and behavior psychology of a T2D patient using GH-Method: mentality-personality modeling via mathphysical medicine. eclaire MD Foundation, USA.

4. Hsu Gerald C (2020) Quantitative measurements of stressors and symptoms for people with Borderline Personality Disorder before and during COVID-19 quarantine period using GH-Method: math-physical medicine. Eclaire MD Foundation, USA.

5. Hsu Gerald C (2020) Using artificial intelligence technology to overcome some behavioral psychological resistance for diabetes patients on controlling their glucose level using GH-Method: mathphysical medicine \& mentality-personality modeling. eclaire MD Foundation, USA. 
6. Hsu Gerald C (2020) Using GH-Method: math-physical medicine mentality-personality modeling, and segmentation pattern analysis to compare two clinic cases about linkage between T2D patient's psychological behavior and physiological characteristics. eclaire MD Foundation, USA.

7. Hsu Gerald C (2020) Trending pattern analysis and progressive behavior modification of two clinic cases of correlation between patient psychological behavior and physiological characteristics of T2D Using GH-Method: math-physical medicine \& mentality-personality modeling. Eclaire MD Foundation, USA
8. Hsu, Gerald C (2020) Using wave characteristic analysis to study T2D patient's personality traits and psychological behavior using $\mathrm{GH}-$ Method: math-physical medicine. Eclaire MD Foundation, USA

9. Hsu Gerald C (2020) Using wave characteristic analysis to study a diabetic patient's personality traits and psychological behavior (mathphysical medicine) Eclaire MD Foundation, USA.

10. Hsu Gerald C (2020) Using a quantitative wave characteristic analysis to provide an initial look of type 2 diabetes patient's personality traits and psychological behavior on glucose control (math-physical medicine). Eclaire MD Foundation, USA.

\section{Your next submission with Juniper Publishers will reach you the below assets}

- Quality Editorial service

- Swift Peer Review

- Reprints availability

- E-prints Service

- Manuscript Podcast for convenient understanding

- Global attainment for your research

- Manuscript accessibility in different formats

( Pdf, E-pub, Full Tsext, Audio)

- Unceasing customer service

Track the below URL for one-step submission https://juniperpublishers.com/online-submission.php 